\title{
Female genital mutilation in Southern Iran
}

\author{
Mahshid Bokaie ${ }^{1}$, Zahra Bostani Khalesi ${ }^{2}$, Nasibeh Roozbeh ${ }^{3}$, Shahnaz Mojahed ${ }^{1}$
}

1: Research Center for Nursing and Midwifery Care, Shahid Sadoughi University of Medical Sciences, Yazd, Iran. 2: Social Determinants of Health Research Center, Gilan University of Medical Sciences, Rasht, Iran.

3: Mother and Child Welfare Research Center, Hormozgan University of Medical Sciences, Bandar Abbas, Iran. DOI: https://doi.org/10.4314/ahs.v20i2.16

Cite as: Bokaie M, Khalesi ZB, Roozbeh N, Mojahed S. Female genital mutilation in Southern Iran. Afri Health Sci. 2020; 20(2): 666-667. bttps://doi.org/10.4314/abs.v20i2.16

Female Genital Mutilation (FGM) is defined by the World Health Organization as "partial or total removal of the external female genitalia or other injury to the female genital organs". Between 100 -140 million adolescents and females in the world are predicted to suffer such procedures, and nearby 3 million girls are expected to be at risk of undertaking the procedures every year. FGM has been reported to happen in all parts of the world ${ }^{1}$. The FGM have adverse complication such as hemorrhage, psychological consequences, infection, shock and sexual dysfunction. Attitudes about FGM can be prejudiced by one's own opinions and the ethnic and cultural background in which care is provided. So, it is imperative that there are chances for health providers to find out these effects and report their own attitudes to avoid stigmatization around FGM, which could end result in incorrect care of girls who have already suffered $\mathrm{FGM}^{2}$. FGM is a deeply engrained cultural tradition detected primarily in Africa and the Middle East and Asia. It has great health concerns. Improved awareness of the laws against FGM will allow the provider to train and advise at-risk girls as well as their parents ${ }^{3}$.This custom exists in some province in Iran such as Qeshm Island in Hormozgan province ${ }^{4}$. The aim of this study was to describe why FGM is still common in this part of Iran.

\section{Corresponding author:}

Zahra Bostani Khalesi,

Social Determinants of Health Research Center, Gilan University of Medical Sciences, Rasht, Iran. Email: Z_bostani@yahoo.com
Due to negative outcomes of FGM among women, this qualitative field study carried out among 13 women and five health provider in Qeshm from May until July 2017. Most of women were aged 20 to 45 years and the level of education of them was diploma. Many women in Qeshm have a positive attitude towards FGM and did not believe this action causing sexual problems. Some of the misconceptions about FGM were: Divorce is less in girls with female genital mutilation than others, FGM prevents them from infertility, men preferred to marry with this girl, FGM prevent girls from rape, and this girls deliver more sons.

Health provider in Qeshm were 35- 48 years old. They confirmed: The woman who does circumcision was often elderly and lives in the local area. This job was hereditary and they used traditional tools. This procedure is performed without local anesthesia. In some cases, part of the clitoris is removed, but today in most cases, they just cut the razor onto it. Factors such as education level and occupation have no significant effect on its reduction.

\section{Conclusion}

Prevalence of FGM in many areas of Iran remains high, conferring WHO goals to eliminated FGM, both increased funds and management and collaboration are needed. Due to the results of this study female genital mutilation is socio-cultural custom and many of women in this area had positive attitude to this procedure. Health care provider need to change their attitude to this procedure by education meeting with people.

\section{Ethical issues}

Not applicable. 
Conflict of interest

None.
Financial Support

None.

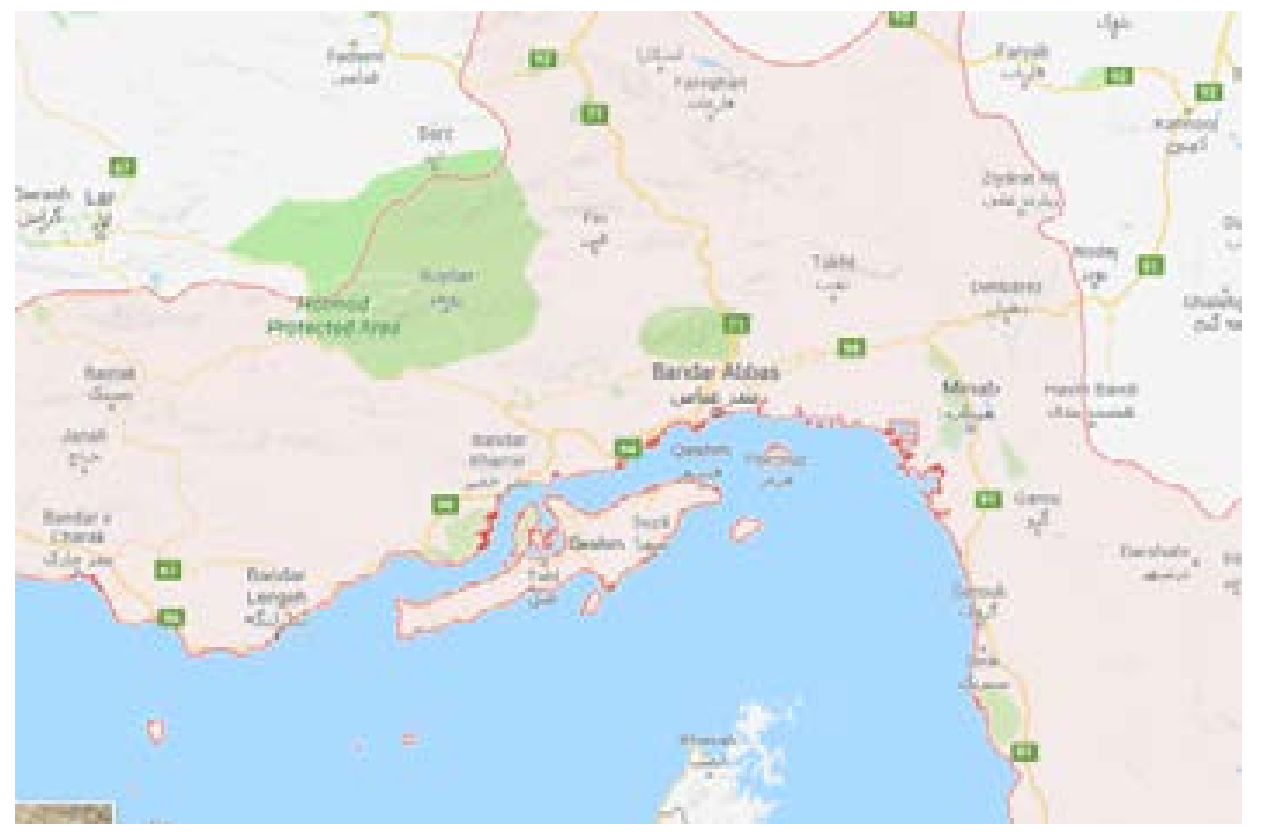

\section{References}

1. World Health Organization DoRHaR. Eliminating Female Genital

Mutilation: An Interagency Statement. 2008. Geneva: World Health Organization. World Health Organization; 2016. p. 48.
2. Pashaei T, Rahimi A, Ardalan A, Felah A, Majlessi F. Related factors of female genital mutilation (FGM) in Ravansar (Iran). J Women's Health Care. 2012;1(2):1000108. 3. Kelly E, Hillard PJA. Female genital mutilation. Current Opinion in Obstetrics and Gynecology. 2005;17(5):490-4. 4. Mozafarian R. Female Circumcision in Qeshm. Iran Nameh. 2012;27(1):50-60. 